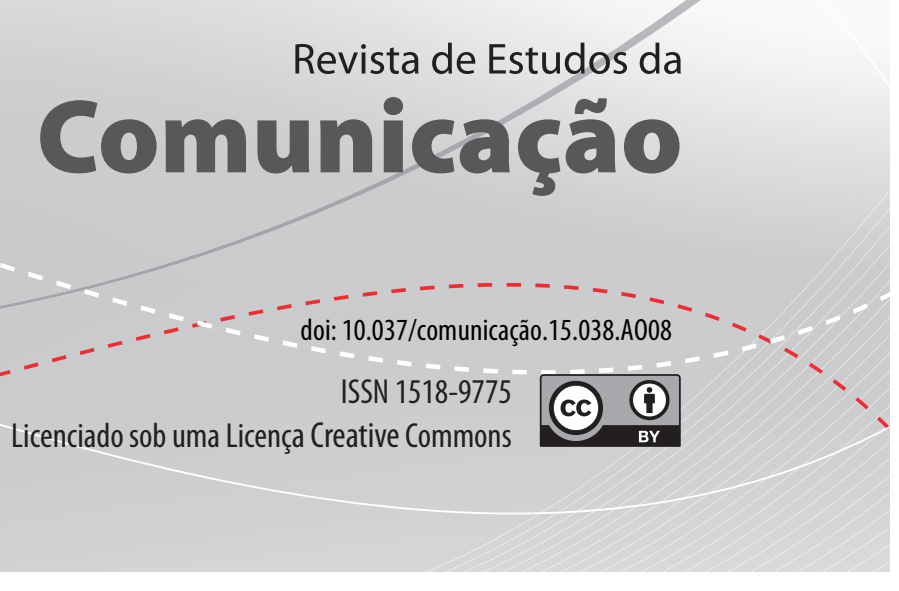

\title{
Fazendo faxina no Facebook: implicações do gerenciamento e comunicação com a Rede de Contatos para Dinâmicas de Autoapresentação'
}

Cleaning up Facebook: implications of network management and communication for Self-Presentation Dynamics

\section{Beatriz Bandrão Polivanov}

Doutora, Universidade Federal Fluminense (UFF), Niterói, RJ, e-mail: beatriz.polivanov@gmail.com

\footnotetext{
Uma versão anterior deste trabalho foi apresentada no GP Cibercultura, coordenado pela prof. Dra. Adriana Amaral, do XIV Encontro dos Grupos de Pesquisa em Comunicação, evento componente do XXXVII Congresso Brasileiro de Ciências da Comunicação (Intercom), Foz do Iguaçu, setembro de 2014.
} 


\section{Resumo}

O trabalho tem como objetivo discutir, a partir de revisão da literatura e pesquisa empírica de cunho etnográfico, como atores sociais gerenciam suas redes de contatos no site de rede social Facebook e investigar quais as implicações desse processo para dinâmicas de autoapresentação. Para tal, utiliza-se o conceito de friendship performance proposto por Boyd e Ellison (2007), em diálogo com outros autores que se debruçam sobre questões relacionadas à sociabilidade e construção identitária nessas plataformas. Conclui-se que um dos aspectos que diferencia o Facebook de outros ambientes é o fato de que nele frequentemente fazem parte da rede de contatos de um ator pessoas com as quais convive em contextos sociais distintos, fazendo com que tenha que gerenciar suas amizades de modo autorreflexivo e constante.

Palavras-chave: Facebook. Rede de contatos. Performance da amizade. Autoapresentação.

\section{Abstract}

This paper aims to discuss, based on literature review and an ethnographic research carried out in 2012, how social actors manage their networks in the social network site Facebook, and also investigate the implications of this process for dynamics of self-presentation. In order to do that Boyd and Ellison's concept of friendship performance (2007) is used, in a dialogue with other authors who study matters related to sociability and identity construction in these platforms. In conclusion, one of the aspects which differentiates Facebook from other environments is the fact that in the first usually one has to share people from different social contexts in their same network, which makes them manage their friendships in a self reflexive and constant way.

Keywords: Facebook. Network. Friendship performance. Self-presentation.

\section{Introdução}

A já vasta e multidisciplinar bibliografia sobre os chamados sites de redes sociais e suas diversas apropriações, funcionalidades e implicações tecnoculturais corrobora para que se coloque tais objetos em evidência no cenário midiático contemporâneo. Como afirma Livingstone, "em termos de affordances, os sites de redes sociais possibilitam a comunicação entre círculos cada vez maiores de contatos", permitindo "a convergência de atividades, até então separadas, de e-mails, mensagens, criação de websites, diários, álbuns de fotografias e uploading e downloading de músicas ou vídeos" e, principalmente, configurando uma "maneira 
integral de gerenciar sua própria identidade, seu estilo de vida e suas relações sociais" (LIVINGSTONE, 2012, p. 93).

Dessa forma, eles têm se destacado por permitirem que os atores sociais sejam os centros de suas próprias comunidades (BOYD; ELLISON, 2007, online), em torno das quais são geradas conversações e trocas de arquivos de cunhos distintos. O gerenciamento de tais conteúdos - como fotos, vídeos e textos que ficam atrelados aos perfis - é feito pelos próprios usuários, dando-lhes certa autonomia ${ }^{2}$ para autoadministrarem as imagens que desejam construir de si nos sites de redes sociais.

No entanto, chama a atenção aqui para outro aspecto fundamental dessas dinâmicas de construção de si em sites de redes sociais: o gerenciamento das próprias relações sociais, isto é, das redes de contatos dos atores nessas plataformas. Partindo da premissa de que os atores sociais estão sempre em face de um público, uma audiência, para a qual performatizam seus selves (GOFFMAN, 2009), busca-se entender aqui como determinados atores gerenciam suas redes de contatos no site de rede social Facebook ${ }^{3}$, resgatando o conceito de friendship performance proposto por Boyd e Ellison (2007), e de que modos tal processo está atrelado às suas dinâmicas de autoapresentação no site, isto é, às formas como desejam se apresentar aos olhares dos outros. Conforme defendem as autoras, as “'exibições públicas de conexão' servem como importantes pistas identitárias" no sentido de que "uma rede estendida pode servir para validar informações de identidade apresentadas nos perfis" (BOYD; ELLISON, 2007, online), estando diretamente ligadas, portanto, a como os atores se apresentam no site.

Assim, destacam-se as seguintes questões, sobre as quais se busca lançar luz neste trabalho: de que formas as redes de contatos dos atores sociais no Facebook estão relacionadas com suas autoapresentações? Até que ponto eles estariam conscientes sobre quem compõe sua "audiência" no site? Como suas dinâmicas conversacionais e de sociabilidade influenciam nessa autoconstrução perene?

De modo a responder tais questões, empreende-se um estudo qualitativo de cunho etnográfico, entendendo que "a pesquisa qualitativa visa uma compreensão aprofundada e holística dos fenômenos em estudo e, para tanto, os contextualiza e reconhece seu caráter dinâmico" (FRAGOSO; RECUERO; AMARAL, 2011 , p. 67). De julho a setembro de 2012 , entrevistas presenciais semiestruturadas com cinco residentes da cidade de São Paulo foram realizadas, além da obser-

\footnotetext{
Sob o atento olhar e gerenciamento também das próprias empresas donas dos diversos sites de redes sociais, que podem, por exemplo, retirar dos sites conteúdos que violem suas políticas de uso. Mais do que isso, conforme se vai argumentar, o processo de construção de si é sempre auto e alo definido, por isso, a ênfase a "certa" autonomia.

Site de rede social com maior número de usuários no mundo, ultrapassando a marca de um bilhão de usuários ativos. Disponível em: <http://www.statista.com/statistics/264810/number-of-monthlyactive-facebook-users-worldwide/>. Último acesso em: 11. jul. 2014.
} 
vação de seus perfis individuais no Facebook. Os informantes, três do sexo masculino e duas do sexo feminino, possuíam então entre 29 e 38 anos de idade, autodenominavam-se como parte da "classe média brasileira" e tinham as seguintes profissões: fotógrafa, produtor musical, produtores de eventos e gerente de sustentabilidade empresarial ${ }^{4}$. De agora em diante, eles serão identificados como C., D., M., N. e J., respectivamente, mantendo suas identidades preservadas.

Curiosamente as falas dos informantes durante as entrevistas apontaram para o processo de "fazer faxina" ou "fazer uma limpeza" no Facebook - usando especificamente tais termos, o que inspirou o título do trabalho - referindo-se ao processo de periodicamente checar quem são as pessoas que fazem parte de sua rede de contatos no site e selecionar aqueles que devem permanecer como tal e aqueles que não, devido a razões distintas, exploradas no artigo, bem como suas implicações para as dinâmicas de autoapresentação.

Assim sendo, o trabalho se divide em duas partes principais: "Performance da amizade no Facebook", na qual se aplica o conceito de Boyd e Ellison para analisar o material empírico obtido com o estudo, e "Formas de interação com a rede de contatos", na qual se busca entender quais recursos do site - como trocas de mensagens textuais privadas e (semi) públicas, uso do botão "curtir", dentre outros são utilizados pelos informantes para interagir com suas redes de contatos e de que modos.

Buscam-se assim pistas para entender os conflitos e negociações relacionados ao processo de apresentação de si no Facebook especificamente no que tange ao gerenciamento das redes de contatos dos atores sociais. O foco recai principalmente, portanto, no gerenciamento das amizades e também nos modos como os atores interagem com suas redes, entendendo que tais práticas de interação "se revelam como geradoras de referenciais identitários que servem de base para as expressões e os comportamentos sociais nos sites" (RIBEIRO; BRAGA, 2012, p. 70).

\section{Performance da Amizade no Facebook}

O Facebook, vale lembrar, é um website gratuito - cuja receita é proveniente de publicidade - que tem como finalidades principais permitir que pessoas se comuniquem virtualmente por meio de mensagens semipúblicas ou privadas e que publiquem imagens, textos e vídeos de seu interesse, sendo fundamental um aspecto do site: a criação de perfis, geralmente individuais, por meio do quais os usuários se identificam e se apresentam para a sua rede de contatos, composta por

\footnotetext{
É importante destacar que os cinco informantes participaram de uma pesquisa mais ampla ealizada pela autora anteriormente sobre construção identitária em sites de redes sociais.
} 
aqueles com os quais poderão se comunicar diretamente e cuja "afiliação" ao usuário fica visível para outros que são cadastrados no site.

Devido a essas três características-chave - a criação de perfil, a (semi) publicização da rede de contatos dos usuários e a interação via mensagens (semi) públicas ou privadas - o site é classificado como um site de rede social (BOYD; ELLISON, 2007). O Facebook é considerado ainda como um site de rede social "estruturado" ou "propriamente dito" (RECUERO, 2009) devido a tais características e ainda ao fato de que nele as relações sociais são recíprocas ou bilaterais, isto é, quando um usuário adiciona um "amigo" ${ }^{5}$ no site ambos, o usuário que o adicionou e seu "amigo", passam a figurar na rede de contatos um do outro. Tal relação não se dá em sites de redes sociais considerados "apropriados" - como o Twitter ${ }^{6}$ - nos quais se pode "seguir" um determinado usuário, passar a acompanhar as postagens em seu perfil, sem necessariamente ser "seguido" por ele, configurando uma relação não recíproca.

De acordo com Miller, as atividades que mais consomem tempo dos usuários de Trinidad no Facebook são, nesta ordem, a comunicação, jogos online e o cultivo do perfil, sendo este último um "modo de refinar como uma pessoa aparece para o mundo externo através do que você escolhe estar associado" (MILLER, 2011, p. 80). Dessa forma, interessa aqui investigar não com "o que", mas com "quem" os atores se relacionam e sociabilizam em suas redes no site e quais são as dinâmicas comunicacionais que se configuram nessas relações, entendendo que "o processo de construção das imagens de si nos SRS parece exercer papel significativo no processo de formação e controle dos laços sociais contemporâneos" (RIBEIRO; NAJM; MIRANDA, 2012, p. 11).

Averiguou-se o tipo de rede de contatos prioritário que os informantes mantinham no site, isto é, se sua rede era de cunho primordialmente pessoal ou profissional ou ainda "bem dividido entre os dois", o que certamente leva a distintos modos de performance da amizade (BOYD; ELLISON, 2007), uma vez que os atores sociais desempenham diferentes papéis sociais e tendem a se performatizar de modo distintos para as diversas plateias para as quais se apresentam (GOFFMAN, 2009; LIVINGSTONE, 2012; RECUERO, 2009; RIBEIRO; BRAGA, 2012).

Como alguns dos informantes trabalham com produção de eventos e música, é necessário que estejam em contato permanente e diretamente com seu público-alvo e também com outros produtores, o que é facilitado em grande medida pelo Facebook, por ser o "lugar onde todo mundo está", conforme afirmou uma das entrevistadas. Ainda assim, alguns preferem não "misturar" a vida pessoal com a profissional, utilizando o site principalmente para se relacionar com pessoas com as quais têm vínculos afetivos, conforme se discute abaixo.

Denominação usada no próprio site.

Disponível em: <http//: www.twitter.com>. 
A rede de conexões de M. no Facebook é primordialmente de cunho pessoal e atualmente inclui pessoas "da infância, (...) do acampamento, das baladinhas, do clube, do colégio, de uma faculdade, de outra faculdade. Aí hoje em dia tem mãe, tem tia, todo mundo, bebê recém-nascido, primo" ${ }^{7}$. Não obstante, alguns de seus amigos ela conheceu por questões profissionais: "tem algumas pessoas com quem eu me relaciono (...) no meio profissional, mas são pessoas que vieram pra minha vida pessoal. Viraram amigos". Com certa frequência - não definida pela informante - M. realiza o processo mencionado acima de "faxina" no Facebook, checando a sua lista de conexões para averiguar se há pessoas com as quais pouco se relaciona. Se isso for constatado, ela retira (bloqueia) a pessoa de sua rede, como explica: "vire e mexe eu tô fazendo uma limpa. Tipo, ah, não falo com essa pessoa há seis meses. Tchau. Sabe, não tem porque eu ficar guardando amizade pra dizer que eu tenho mais ou menos amigos". J. afirmou fazer o mesmo: "Ah, eu faço isso [rever a lista de contatos] com uma certa frequência, mas eu não faço limpas grandiosas porque eu não saio adicionando muita gente" (J., 2012).

O critério principal dos cinco informantes para adicionarem uma pessoa em sua rede de contatos no site está baseado, segundo suas falas, em já conhecê-la previamente off-line, corroborando os achados de Boyd e Ellison (2007) que afirmam que a maioria das pessoas adicionadas em sites de redes sociais como Facebook e Orkut - aqueles que estariam baseados em relações de afeto (POLIVANOV, 2011) - seriam já conhecidas em ambientes off-line. De acordo com a informante M.: "não adiciono ninguém que eu não conheça ou que não tenha tido o mínimo de relação no mundo de fora do Face". E quando a informante adiciona alguém por razões profissionais, ela posteriormente, finda a parceria de trabalho, bloqueia a pessoa do Facebook, a não ser que elas passem a constituir um vínculo afetivo e pessoal.

As falas dos outros informantes ressaltam o mesmo critério:

ultimamente eu só tô adicionando quem eu conheço [off-line]. É, porque senão perde o controle. (...) é tua vida ali, né, (...) na verdade eu preciso fazer uma faxina no meu Facebook. (C., 2012).

pelo menos $95 \%$ das pessoas são pessoas que eu conheço mesmo, mesmo, mesmo [off-line] (...) obviamente eu não mantenho contato com todas essas pessoas, eu não tenho tempo pra isso. Mas é uma maneira de tá ali, onipresente. Inclusive, o Facebook é muito isso, é... eu tô ali onipresente... (J., 2012). 
no meu Facebook, se eu não conhecer a pessoa eu já não adiciono. (...) A todo tempo, ficam sempre as que de uma certa forma, tem contato comigo. (...) Isso eu tenho certeza. Eu posso falar quem é cada pessoa. (N., 2012).

N. questionado se de fato conhecia, off-line, as mais de 800 pessoas que tinha em sua lista de contatos no site (naquele momento), ele respondeu que sim, fazendo a ressalva apenas que "pra não falar todas, tem 8 ou 9 pessoas que eu não conheço face a face. (...) 1 ou $2 \%$ [da rede de contatos], vai. Que são pessoas, por exemplo, que eu conheci no Twitter, que a gente conversa muito, e acabaram adicionados ali" (N., 2012).

O Facebook funcionaria, assim, para eles mais como uma plataforma para agregar as pessoas que já conhecem e com quem já estabeleceram laços sociais (como um "social network site" conforme propõem Boyd e Ellison, 2007) do que para adicionar e passar a conhecer pessoas "novas" (social networking site), conhecidas por meio do site ou outros ambientes virtuais. Assim, ao gerenciarem suas impressões no site, esses atores têm de levar em consideração que seu público, sua audiência no site, é composta primordialmente de pessoas que conhecem offline, o que, por um lado, leva ao argumento de que os perfis nos sites de redes sociais não devem ser pensados como ambientes em que há uma superexposição aleatória dos atores, uma vez que se tratam de lugares nos quais se dirigem a um público específico, majoritariamente de pessoas conhecidas, com as quais já se relacionam e que pressupõem, assim, um determinado grau (mesmo que seja mínimo) de intimidade.

Por outro lado, ainda que esse público seja basicamente composto de pessoas conhecidas, outro dado relevante a se levar em conta é que se trata de contatos de origens e relacionamentos distintos, como pessoas da família, amigos de lugares e épocas diferentes e pessoas com quem mantêm distintas relações profissionais (ainda que essas também possam, é claro, se tornar amigas), o que requer dos atores que administrem de modo autorreflexivo (GIDDENS, 2002) a(s) impressão(ões) que querem passar de si no site para uma gama variada de pessoas, com as quais mantêm diferentes relações e com as quais criam laços sociais fortes e fracos ${ }^{8}$.

Conforme relataram alguns dos informantes, há dificuldade neste gerenciamento no Facebook, uma vez que os atores exercem, cotidianamente, diversos papéis sociais e assumem, portanto, diariamente diversas facetas distintas de suas personalidades (GOFFMAN, 2009) e no site devem levar em consideração toda essa

\footnotetext{
Conforme explica Recuero, "laços fortes são aqueles que se caracterizam pela intimidade, pela proximidade e pela intencionalidade em criar e manter uma conexão entre duas pessoas. Os laços fracos, por outro lado, caracterizam-se por relações esparsas, que não traduzem proximidade e intimidade" (2009, p. 41).
} 
diversidade de papéis e facetas em sua autoapresentação, corroborando a ideia de que "criar identidade e relações sociais on-line não só demanda tempo e é às vezes arriscado, mas também pode ser difícil de gerenciar" (LIVINGSTONE, 2012, p. 108).

N., por exemplo, não se relaciona com pessoas da família pelo Facebook (nem do trabalho), uma vez que, segundo o informante, ele não é ele mesmo no site. Ele afirma ter construído um personagem de si mesmo no Facebook:

Do mesmo jeito que a galera do trabalho, também está fora. A galera da família, também está fora. (...) Eles estão ali, mas estão bloqueados [para ver o perfil completo de N.] (...) É porque é o que eu falei, ali não sou eu, entendeu? E você acaba sendo julgado por algumas coisas (N., 2012).

Aqui é importante destacar a estratégia utilizada por N. para lidar com seus diferentes públicos no Facebook: o informante ajusta as configurações de privacidade de seu perfil para que determinadas pessoas (como aquelas com quem trabalha e sua família) não tenham acesso ao seu perfil completo, mas somente a informações mais gerais como seu nome, foto de perfil, foto de capa, local onde trabalha e cidade onde mora. Dessa forma, "no âmbito do controle social implicado na autorrevelação, é possível manejar as ferramentas de configuração da privacidade dos perfis, como alternativa para ampliar o controle das audiências potenciais da autorrevelação (ELLISON et al., 2011)" (RIBEIRO; NAJM; MIRANDA, 2012, p. 9). Os perfis podem ser considerados, assim,

um lugar de controle, permitindo aos participantes determinarem quem pode ver o que e como. Enquanto os perfis de sites de redes sociais podem ser acessíveis a qualquer um - "realmente públicos" - é comum aos participantes limitarem a visibilidade de seus perfis, tornando-os "semi-públicos". Perfis semipúblicos estão ainda tipicamente disponíveis a um público mais amplo, formado por amigos, conhecidos, pares e laços periféricos interessantes. Neste sentido, os perfis são onde a audiência potencial está fixada, criando um público mais estreito formado por conexões e afiliações explícitas (BOYD, 2011, p. 5, tradução livre nossa).

Ribeiro, Najm e Miranda se apoiam na ideia de que os sites de redes sociais criam um novo gênero de público, que seria o networked publics (públicos em rede), isto é, "públicos que são reestruturados pelas tecnologias em rede" e que são, simultaneamente, o lugar construído por meio dessas tecnologias e o "coletivo imaginado que emerge como resultado da interseção entre pessoas, tecnologia e prática" (BOYD, 2011, p. 1). Nesse sentido, três dinâmicas marcam esses públicos em rede, quais sejam: 
(1) Audiências invisíveis: nem todos os interlocutores são/estão visíveis quando as pessoas publicam informações online; (2) Contextos colapsados: a falta de clareza quanto à delimitação de fronteiras espacial, social e temporal complexifica a percepção e a consequente distinção de contextos; (3) Fluidez entre público e privado: sem controle sobre o contexto, o binário público e privado tornase complexo, deixando suas fronteiras e noções cada vez mais confusas (RIBEIRO; NAJM; MIRANDA, 2012, p. 4).

Dessa forma, destaca-se que "os amigos incorporados à lista compõem a audiência imaginada (intencionada) que poderá acompanhar a autorrevelação" (RIBEIRO; NAJM; MIRANDA, 2012, p. 8) dos atores nos sites de redes sociais e que essa audiência é

a lista de amigos que eles escolheram para se conectarem no site. É quem os participantes esperam que vão acessar seus conteúdos e interagir com eles. E essas são as pessoas a quem o participante está direcionando suas expressões. Ao servir como a audiência imaginada, a lista de amigos funciona como o público intencionado. Claro que apenas porque essa coleção de pessoas é o público intencionado não significa que seja o público real. Ainda assim, o valor de imaginar a audiência ou público é para ajustar o comportamento e autoapresentação de alguém para se adequar às normas intencionadas daquela coletividade (BOYD, 2011, p. 6, tradução livre nossa).

Além disso, há níveis variados de consciência ou conhecimento que os atores podem ter sobre quem compõe sua audiência imaginada (intencionada) nos sites de redes sociais. Os informantes desta pesquisa relataram um alto grau de preocupação, controle e consciência sobre como determinam e gerenciam sua rede de contatos no Facebook, ainda que por vezes tenham dificuldade em fazê-lo (J., por exemplo, vive em constante conflito em relação a isso, entrando e saindo do Facebook com frequência justamente pela dificuldade de lidar com essa questão), recorrendo a mentir para determinadas pessoas, como é o caso de C. A informante relata ter dificuldades para administrar sua rede de contatos no site, principalmente em relação à sua sobrinha mais nova e à sua mãe, mas não por ter construído um personagem pelo qual pudesse ser "julgada", e sim por ser ela "mesma", por postar fotos das festas que frequenta e de ensaios fotográficos mais "ousados" que faz, para citar alguns exemplos de conteúdos aos quais ela não gostaria que as duas tivessem acesso: 
Eu tive que bloquear a minha sobrinha mais nova, porque a minha mãe pedia pra ela ficar entrando no meu Facebook (Risos). "Ai, tia, não consigo te ver". "Pois é, menina, esse Facebook..." Têm várias pessoas que não me veem. (Risos). Pois é, o resto da minha família não me importo de ver as minhas coisas. É assim, é que minha mãe, ela é muito careta, entendeu? Ela não vai entender, as outras pessoas da minha família me conhecem, sabem como eu sou, entendeu? (C., 2012).

J., que se comunica com a avó que mora no exterior por meio do Facebook, também destaca dificuldade de lidar com a sua presença na rede de contatos, uma vez que se sente pressionado não apenas a se manter no site, pois é o principal meio de comunicação entre eles, mas também a de ter que lidar com a vigilância da avó sobre os conteúdos que posta, considerados por ela muito agressivos:

eu recebi uma mensagem da minha vó, "querido saudade sua, de ver sua fotinha que, inclusive, não encontrei no Facebook", ela me mandou isso [por e-mail] (...) ela sempre entra no Facebook pra me ver. Pra ver o que que eu escrevi, como está minha vida (...) teve uma vez na foto (...) de capa (...) E por um bom tempo tinha a foto de um lobo (...) E minha vó meio que, "meu filho cê está... está muito agressivo, tô vendo foto sua", eu falei: "vó, queria que eu tivesse o quê? Se tivesse foto de anjinho obeso, você ia ficar feliz? Sabe, tipo, você vê anjo eu vejo lobo porra”, já mandei uma revanche atravessada (J., 2012).

O informante sente dificuldade similar para lidar com as pessoas do seu meio profissional que o procuram no Facebook, uma vez que seu perfil no site tem muitas imagens consideradas "pesadas", relacionadas a uma estética gótica, e muito material do qual se apropria ou cria como formas de expressão pessoal ${ }^{9}-$ por meio das próprias fotos e também músicas e frases que posta - que não gostaria de compartilhar com colegas de trabalho. Conforme o entrevistado:

eu ando num certo conflito com relação ao Facebook e até pensei em criar dois perfis. Porque, às vezes, tem gente do trabalho que me adiciona, mas (...) uma coisa é a postura que eu tenho profissional (...) antes do meu nome tava lá minha foto bunitinha (...) tava lá [seu nome verdadeiro]. Cara, já mudei já pra [nome falso, mas similar ao verdadeiro], porque eu não quero que ninguém fique me identificando, me achando sabe? Muita gente, ainda mais agora que eu mudei de trabalho, aí muita gente quer procurar. Eu falo: “cara, mas num é Fa-

\footnotetext{
O informante afirma em outro momento que "(n)o Facebook, pelo menos pra mim, é muito mais uma expressão, eu me expresso" (J., 2012).
} 
cebook". Num é bem a ferramenta que eu utilizo pra esses fins de contato sa$b^{10}$. (...) Mas é muito difícil também, hoje em dia, você separar uma coisa da outra [vida pessoal da profissional e vice-versa] (...) tudo que você disser pode ser jogado contra você (...) eu não quero que isso se misture (J., 2012).

Assim, por mais que os informantes relatem tais dificuldades em gerenciar suas redes de contatos e sua autoprodução no Facebook (ou justamente por isso), fica claro o alto grau de consciência que eles têm sobre quem faz parte de sua audiência no site, levando a diversas estratégias para lidar com elas. Não obstante, trabalhos como o de Livingstone (2012) e de Ribeiro, Najm e Miranda (2012) questionam se os usuários mais jovens de sites de redes sociais, no caso os adolescentes, por vezes não se dariam conta de quem é a audiência para a qual publicam seus conteúdos, podendo ainda ter dificuldades de ordem tecno-cognitivas para configurar no site as opções de privacidade e eles acabariam revelando, dessa forma, "informações pessoais até para várias centenas de pessoas que eles conhecem apenas casualmente" (LIVINGSTONE, 2012, p. 108).

O que interessa problematizar, no entanto, é que tipos de conteúdos são considerados passíveis de publicização pelos informantes e que tipos não o são, entendendo que "os sites de relacionamentos sociais tipicamente mostram como padrão exatamente as informações pessoais que as gerações anteriores frequentemente consideram como particulares (especialmente idade, política, renda, religião, preferência sexual)" (LIVINGSTONE, 2012, p. 108). Ou seja, tratar-se-ia, portanto, de uma reconfiguração das próprias noções de esfera pública e privada ou, ainda, de uma diluição de fronteiras entre elas (BOYD, 2011; RIBEIRO; NAJM; MIRANDA, 2012), questão na qual não se aprofundará neste trabalho.

É importante destacar ainda que a rede de contatos que o ator constrói no Facebook (e em outros SRSs) é também, por si própria, um importante marcador identitário e performático. Isto é, para além de construir uma audiência imaginada (intencionada) para quem se expressar e com quem deseja interagir, o próprio fato de ter aquelas pessoas na rede de contatos de um ator já marca, de certa forma, quem ele(a) é ou deseja ser, a partir das pessoas com as quais deseja se afiliar. Além disso, a partir do momento em que interage com aquelas pessoas, o ator passa também a ser construído por essas interações, não tendo, portanto, total controle sobre a persona que busca criar (WALTHER ET AL., 2008), configurando o que Matuck e Meucci (2005) denominaram de "alo-definição", isto é, a definição do eu pelos outros, complementando o processo de autodefinição.

A fala de D., ao relatar como seleciona as pessoas que aceita para compor sua rede de contatos no Facebook, ilustra esse ponto, uma vez que o informante

10 Para contatos profissionais, afirmou utilizar telefone e e-mail profissional. 
destaca que não adiciona pessoas que "não tenham nada a ver" com ele, seus interesses e gostos:

Se não é uma coisa de um conhecido, eu não aceito, porque... cara, às vezes a festa não tem nada a ver comigo, entendeu? (...) Senão, é coisa de um conhecido e tem a ver comigo. Eu até aceito. (...) Ah, a gente dá uma olhada no que a pessoa posta, né? O problema, às vezes, é que a pessoa... você não tem como ver. Daí você aceita, dá uma olhada. "Puta, isso aí não tem nada a ver comigo". Eu vou lá e deleto (D., 2012).

Assim, ao aceitar uma determinada pessoa para fazer parte de sua rede de contatos, algo que fica público a todos que tiverem acesso a seu perfil, os atores aceitam também - em níveis certamente variados de consciência - que essas pessoas constituirão a persona que estão elaborando no site, seja simplesmente pela afiliação entre si, seja pelas interações entre elas (RECUERO, 2009). Agora, portanto, o artigo se atém às formas como os informantes interagem com sua rede de contatos no Facebook.

\section{Formas de Interação com a Rede de Contatos}

De acordo com Berto e Gonçalves, "o Facebook viabiliza uma forma de interação social complexa, na qual diferentes signos relacionam-se para compor a mensagem" (2011, p. 101). Para os autores o site permite a concentração de "semioses presentes em diversos outros gêneros emergentes" (p. 104), dentre as quais, pode-se destacar: 1) a escrita; 2) a associação de fotos, conteúdos audiovisuais e imagéticos; 3 ) a convergência entre as diversas plataformas digitais por meio da postagem de links; e 4) a possibilidade de comunicação não verbal (p. 105). Um quinto e último tipo de recurso, além dos já mencionados, são as ferramentas "curtir" (botão "like", que permite que se expresse aprovação ou apoio sobre conteúdos diversos publicados no site ou ainda pode apenas sinalizar que a mensagem foi lida), "compartilhar" (ferramenta que permite o compartilhamento de postagens de outrem na página de um usuário) e "cutucar" (ação exercida por um ator social sobre outro, buscando chamar a sua atenção e manter o laço social estabelecido), todas marcadas pela mistura entre a comunicação não escrita e não verbal, que seriam opções comunicacionais exclusivas do Facebook ${ }^{11}$.

\footnotetext{
11 Devido ao fato de o Facebook permitir, em uma única plataforma, a intersemiose desses recursos, os autores o consideram como um gênero discursivo emergente, discussão que foge ao escopo deste trabalho.
} 
Dentre todas as semioses permitidas pelo site, a escrita seria fundamental, uma vez que é necessária para a "interligação de todos os tipos de comunicação ocorridas no ciberespaço" (BERTO; GONÇALVES, 2011, p. 105-106). Recuero $(2012)^{12}$ reforça que a linguagem nos sites de redes sociais ainda é predominantemente textual e, mais importante, que a linguagem no ciberespaço é performática, uma vez que ela serve não apenas para a comunicação entre atores, mas também para que cada um possa dizer quem é. Desse modo, busca-se mapear nesta seção os principais modos por meio dos quais os informantes interagem com sua rede de contatos no Facebook e o que isso pode implicar em termos da performatização de si e sociabilidade dos atores, sem se deter, no entanto, em aspectos linguísticos ou da conversação (como o faz Recuero, 2012), mas sim nos modos como se dão as interações sociais em si, que podem envolver também conteúdos não verbais, conforme visto acima.

M. destacou duas formas principais de interação: "Comentários [escritos] e curtidas sobre posts e fotos", publicados tanto por ela quanto por pessoas da sua rede. Ambas as formas de interação - também majoritárias para os outros informantes - com sua rede de contatos servem para que a informante mantenha os laços sociais com determinadas pessoas, seja por meio da postagem de comentários textuais (que requerem um investimento de tempo e dedicação um pouco maior que as "curtidas"), seja por meio do "curtir", modo mais rápido e prático de interação. Tais laços, para serem mantidos, devem ser reforçados cotidianamente (RECUERO, 2009) e para isso é necessário que o ator faça (e, se possível, receba) novas postagens em sua página com frequência. É importante destacar que a partir dessas interações estabelece-se não raras vezes um diálogo entre a informante e as pessoas de sua rede que responderam ao conteúdo postado, engendrando, portanto, sociabilidade entre os atores, conforme mostra a fala de outro informante abaixo.

N. também afirmou interagir com a rede de contatos por meio de mensagens privadas, "curtidas", comentários, acessos a conteúdos interessantes postados por pessoas da sua rede e participação em jogos do site. D., por sua vez, identificou os mesmos modos de interação (com exceção dos jogos), mas explica que quando começou a utilizar o Facebook não tinha o hábito de curtir os conteúdos dos amigos, pois achava que não era algo seu e que, por isso, não deveria interferir no conteúdo postado. No entanto, atualmente costuma

12 Em conferência de abertura intitulada "Conversação em rede" no Simpósio "sobre interações e práticas sócio-comunicacionais efetuadas em redes digitais" ocorrido em outubro de 2012 na Universidade Federal da Bahia. Disponível em: <http://gitsufba.net/simsocial/programacao/>. Último acesso em: 20 out. 2014. 
curtir. Ou dar um share no trabalho de uma outra pessoa que eu acho legal. Porque antigamente, nem curtir eu curtia. É, eu era muito assim. "Ah, não é meu, não é meu." Entendeu? Tipo, mas ultimamente (...) já teve gente que eu curti. A pessoa veio em mensagem fechada: "Pô, eu vi que você curtiu. Porra! Obrigada, eu fiquei feliz, porque eu... eu queria ouvir isso de uma pessoa como você" (D., 2012).

Desse modo, as postagens, comentários, "curtidas" e compartilhamentos se tornam rastros na timeline da informante, que acabam também por compor sua persona no Facebook, de modo auto e alo-definido (MATUCK; MEUCCI, 2005). De acordo com Boyd, "tanto as autoexpressões quanto as interações entre as pessoas produzem conteúdo baseados em bits nos públicos em rede" e justamente por se tratarem de bits, e não átomos, deve-se levar em consideração suas propriedades de serem mais fáceis de "armazenar, distribuir e procurar" (2011, p. 7).

A autora propõe quatro affordances que estão relacionadas às propriedades do bits e que, por isso, são centrais para o entendimento dos públicos em rede que são: persistência, replicabilidade, escalabilidade e buscabilidade. 0 primeiro diz respeito ao fato de as expressões online serem automaticamente gravadas e arquivadas. O segundo concerne ao fato de que os conteúdos em formas de bits podem ser facilmente duplicados. O terceiro está relacionado à alta visibilidade potencial de conteúdos em públicos em rede. E, por fim, o quarto diz respeito à possibilidade de os conteúdos serem acessados por busca.

Assim, não é à toa que informantes como C. afirmam que trabalham muito utilizando a ferramenta de mensagem privada (inbox) do Facebook, uma vez que não desejam que toda sua interação fique visível e rastreável no site. A informante afirma que "principalmente por causa do [trabalho] eu preciso falar com os artistas diretamente e aí você não vai botar no mural de ninguém, né?" (C., 2012). "Botar no mural" de alguém significa deixar a mensagem pública em seu perfil, algo que não caberia nem para determinadas conversas de cunho profissional, conforme aponta a informante acima, nem para determinadas conversas de cunho pessoal como, por exemplo, quando a informante afirmou ter tido um namorado estrangeiro com o qual se comunicava principalmente por meio de mensagens privadas no Facebook.

D. também afirma se comunicar primordialmente no Facebook por meio de mensagens privadas: "bate papo fechado. (...) É, eu prefiro sempre aquele chat, porque aquele chat já fica com mensagem pra pessoa, entendeu? ${ }^{13 \prime \prime}$ (D., 2012). Ou seja, trata-se de uma comunicação direcionada e privada entre os atores, diferen-

13 É importante destacar que no Facebook a comunicação não pública se dá por meio de mensagens privadas (inbox / chat) direcionadas somente àqueles com quem se deseja comunicar. 
te, portanto, de quando postam conteúdos em suas timelines, que ficam públicos e visíveis a toda sua rede de contato.

Não se trata, assim, de afirmar que as fronteiras entre o público e o privado somem no Facebook, uma vez que ainda há conteúdos e interações que são tratados de forma oculta e aqueles que se fazem publicamente; o que ocorre é uma reconfiguração dessas fronteiras, em comparação à comunicação mediada anterior aos sites de redes sociais.

\section{Conclusões}

Pensar a autoapresentação dos atores sociais nos sites de redes sociais implica pensar também, conforme argumentado, o papel que a "audiência" exerce nesse processo. Isto é, quando se construí os perfis em sites como o Facebook para quem se está fazendo? A quem se está dirigindo e de que modos? Tal processo é marcado pelo dinamismo e pela autorreflexão, o que ficou evidenciado pelas falas dos informantes que afirmam fazer com certa periodicidade, uma "faxina" no Facebook, retirando pessoas da sua rede de contatos com as quais não desejam mais se comunicar ou que não estejam relacionadas aos seus ideais identitários.

Um dos aspectos que diferencia os sites de redes sociais e, mais especificamente o Facebook, de outros "contextos sociais específicos" on-line é o fato de que no primeiro frequentemente fazem parte da rede de contatos de um ator pessoas com as quais convive em contextos sociais distintos, como profissionais (mais ou menos informais), familiares (mais ou menos próximos), escolares/acadêmicos, esportivos, de lazer (de diferentes tipos), dentre tantos outros, diferentemente de sites de redes sociais voltados para esses contextos, como o Linkedln, que é específico para relações profissionais. Isso, portanto, faz com que os atores tenham que gerenciar suas amizades e autoimpressões no Facebook (BOYD; ELLISON, 2007) de modo autorreflexivo, performatizando-se de formas específicas no site.

Por mais que o Facebook permita atualmente que fotos e postagens sejam vistas apenas por determinados grupos designados pelo usuário, os informantes deste estudo não relataram tal uso, seja por não quererem segmentar seus contatos em grupos e ficar determinando quem terá acesso a cada conteúdo, seja por desconhecerem tal possibilidade. Todos demonstraram ter critérios específicos para aceitar e manter pessoas em suas redes de contatos, sendo os principais conhecê-las previamente off-line e/ou aceitar aquelas que "tenham a ver" com seus selves. Assim, eles buscam não atrelar seus perfis a pessoas que possam romper com a coerência expressiva imaginada que criam para si. Ainda, alguns optam por não deixar seus perfis completamente à mostra para sua rede de contatos, 
permitindo que sejam vistas apenas algumas informações básicas, controlando, portanto, o quanto querem expor de si e para quem.

Mas, deve-se ressaltar que, se fossem observados outros agrupamentos sociais e, portanto, outros informantes, provavelmente os resultados não seriam os mesmos. Ou seja, talvez outros informantes mais jovens (e não heavy users de Facebook), conforme aponta Livinstone (2012), tenham menos autoconsciência sobre os diversos modos de gerenciar seus selves no site. Percebe-se ainda que em determinados momentos as falas dos informantes apontavam para práticas muito específicas de seus contextos pessoais e profissionais - como a dificuldade de expressar no site determinadas facetas mais agressivas ou sensuais de si e ao mesmo tempo ter de lidar com as afetações que tais facetas causam a pessoas da família que fazem parte de sua rede de contatos -, mas em outros momentos seus discursos e práticas de uso do Facebook apontavam para apropriações e questões pelas quais passam potencialmente quaisquer usuários do site - como adicionar prioritariamente pessoas que já conhecem ou com as quais tiveram algum contato prévio.

Por fim, pode-se afirmar que a apresentação que eles fazem de si no Facebook não apenas está diretamente relacionada com a "audiência" intencionada para a qual se dirigem, como também é co-construída com essa audiência, por meio das interações entre si e pelo próprio fato de essa audiência ficar visível no site. Os atores acabam, assim, por criar seu "lugar no mundo" não apenas por meio das suas interações e performances off-line, mas também por meio dos modos como elas se dão no Facebook, sempre em um jogo entre identidade e alteridade.

\section{Referências}

BERTO, M.; GONÇALVES, E. Diálogos online: intersemioses do gênero Facebook. Revista Ciberlegenda, n. 25, p. 100-110, dez. 2011.

BOYD, D. Social Network Sites as networked publics: Affordances, Dynamics, and implications. In: PAPACHARISSI, Z. (Ed.). A Networked Self: Identity, Community and Culture on Social Network Sites. London: Routledge, 2011, p. 39-58.

BOYD, D.; ELLISON, N. Social network sites: Definition, history, and scholarship. Journal of Computer-Mediated Communication, v. 13, n. 1, p. 210-230, out. 2007. Disponível em: <http://onlinelibrary.wiley.com/doi/10.1111/j.1083-6101.2007. 00393.x/full>.

FRAGOSO, S.; RECUERO, R.; AMARAL, A. Métodos de pesquisa para internet. Porto Alegre: Sulina, 2011.

GIDDENS, A. Modernidade e identidade. Rio de Janeiro: Jorge Zahar Editor, 2002. 
GOFFMAN, E. A representação do eu na vida cotidiana. Petrópolis: Vozes, 2009.

LIVINGSTONE, S. Tomando oportunidades arriscadas na criação de conteúdo jovem: o uso pelos adolescentes de sites de redes sociais para intimidade, privacidade e expressão própria. Revista Comunicação, Mídia e Consumo, v. 9, n. 25, p. 91-118, ago. 2012.

MATUCK, A.; MEUCCl, A. A criação de identidades virtuais através das linguagens digitais. Revista Comunicação, Mídia e Consumo, v. 2, n. 4, p. 157-182, jul. 2005.

MILLER, D. Tales from Facebook. Cambridge / Malden: Polity Press, 2011.

POLIVANOV, B. Sites de redes sociais: proposta de classificação com base no público-alvo, temática principal, estrutura e funcionalidade. In: V SIMPÓSIO NACIONAL DA ABCIBER, Florianópolis, 2011. Anais do V Simpósio Nacional da ABCiber. Florianópolis: Universidade Federal de Santa Catarina, 2011.

RECUERO, R. Redes sociais na internet. Porto Alegre: Editora Sulina, 2009.

RIBEIRO, J.; BRAGA, V. Interações em ambientes online de compartilhamento de fotografias: considerações baseadas nas perspectivas interacionista e dramatúrgica. Revista Famecos, v. 19, n. 1, p. 65-82, abr. 2012.

RIBEIRO, J.; NEJM, R.; MIRANDA, T. Auto-revelação em ambientes digitais: reflexões sobre a privacidade de adolescentes em sites de redes sociais. In: SIMSOCIAL (SIMPÓSIO EM TECNOLOGIAS DIGITAIS E SOCIABILIDADE), 2012. Anais do SimSocial. Salvador: Universidade Federal da Bahia, 2012.

WALTHER, J. et al. The Role of Friends' Appearance and Behavior on Evaluations of Individuals on Facebook: Are We Known by the Company We Keep? Human Communication Research, v. 34, n. 1, p. 28-49, jan. 2008. Disponível em: <http://onlinelibrary.wiley.com/doi/10.1111/j.1468-2958.2007.00312.x/abstract>.

Recebido: 11/11/2014

Received: $11 / 11 / 2014$

Aprovado: 20/11/2014

Approved: $11 / 20 / 2014$ 